\title{
المتغير الاسلوبي في الرسم السريالي دراسة تهليلية
}

The methodological variable in the surreal drawing an analytical study

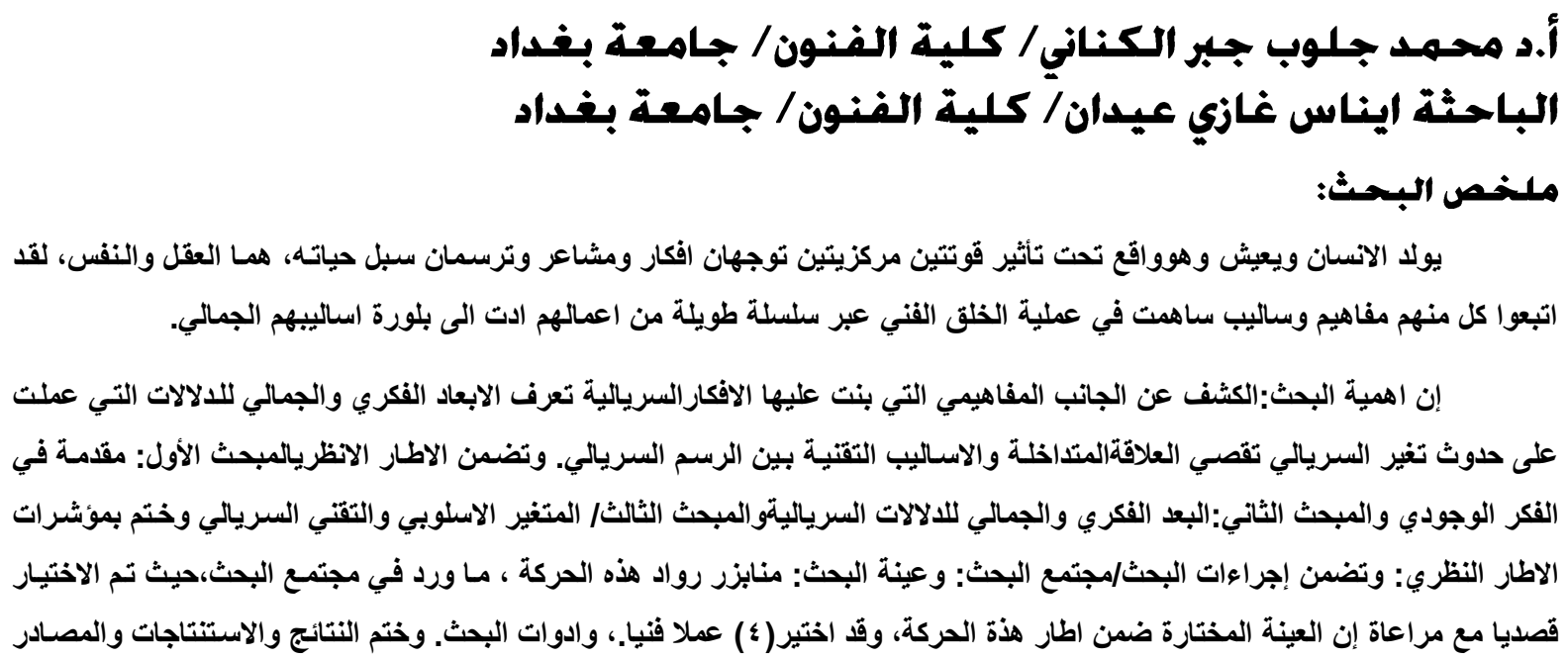

والمراجع.

\section{Summary}

The Surrealist movement, which included the fields of literature, theater and plastic arts, adopted psychological psychology as a way of saying that unconsciousness is a vital and effective part of the life of the individual and society and that the components of the human mind are richer.

This variable has made the artist an active actor who derives his vitality from the freedom that characterized this age. He supplies the civilizational act of civilization to express his ideas and achieve a discourse that is proportionately commensurate with the industry and the creation of its new forms, which have not been invented before.

Thus, technical change is the present basis for the material and cultural means that contribute to the formation of mental structure or the formation of technical data technology.

Through this, the artists of the Serials have followed each of them concepts and methods contributed to the process of artistic creation through a long series of their work led to the crystallization of their aesthetic methods through the meanings contained in their works of art, as it contains the pillars and configurations associated with the concepts of environmental, psychological, philosophical, and spatial, And temporal has to do with the march of the artists and reflected on their art and led to a heterogeneous method among them.

\section{مقدمة بهـ}

يفرد الفنانين السرياليين بقابليتهم على الارتقاء بهذه المشـاعر المبوبـة والرغبـات من مستواها الحسي

المرفوض اجتماعيا الى مستوى جمـالي ابـاعي متميز ومقبول و التسـامي بـالغر ائز والاحاسبس الداخليـة الى لى

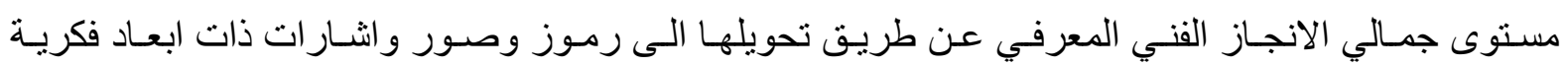

ومعرفية مصاغة باسلوب فني يسمح بتحرير ،هذه الرغبـات والغرائز ودفعها التجاوز عتبـة رمزيـة تعبر عن

انساق اجتماعية متقدمة تحوز على تفدير واعجاب المجتمع ،قد اعتمدت الحركة السريالية التي شملت مجالات 
الادب و المسرح و الفن التشكيلي على طروحات علم النفس النفسي القائلة بـان اللاشعور جزء حيوي وفعال في

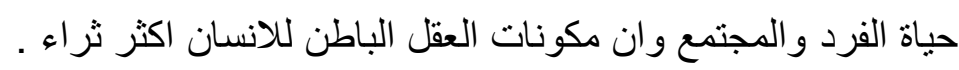
ان هذا المتغير جعل الفنـان في الوقت الحاضـر فـاعلاً يستمد حيويته مـن حريته التي اتسم بها هذا العصر، ومن لوازم الفعل الحضاري العلمي ليعبر عن أفكاره ويحقق خطاباً يتناسب قيمياً مع صناعة وابتكار أثكاله الجديدة غير المجنسة من قبل. لقد انبثق الفن الحديث من رحم الحريـة وقد تكون حريـة الفنان قائمـة على بو اعث عقليـة او ذات طـابع وجداني او قد تكون قائمسة على البـاعثين معـاً. ومعبرة عن منـاخ العصـر الفلسـفي ذا المرجعيـة العقلانيـة او المرجعية الوجودية بهدف تحقيق إرادة الفرد و اختياره وفعله. وبهذا يكون و التغيير التقني بمثابة الحاضر الأساس لما قدم له من وسائط مادية وثقافية تسهم في تشكيل البنية الذهنية او بتشكيل المعطيات المهارية للتقنية. من خلال ذلك كان فنانيين السريالين ولقد اتبعوا كل منهم مفاهيم وساليب ساهمت في عملية الخلق الفني

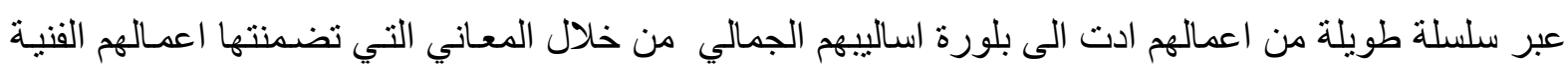
، اذ احتوت اعمالهم على مضاميين وتكوينات مرتبطة بمفاهيمهم بيئية ، ونفسية ، فلسفية ، ومكانية ، وزمانية لها علاقة بمسيرة الفنانيين و انعكست بالتالي على فنهم وادت الى متغاير اسلوبي فيما بينهم . عبر سلسلة طويلة من اعمالهم ادت الى بلورة اساليبهم الجمالي تبحث عن: l. ماهي المتغيرات التي ساهمت في تنوع الاساليب في المدرسة السريالية ؟

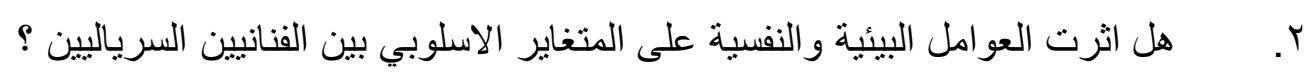
الكثَف عن الجانب المفـاهيمي التي بنت عليهـا الافكـار السـريالية تعرف الابعـاد الفكري والجمـالي للالالات التي عملت على حدوث تغير السريالي تقصي العلاقةالمتداخلة و الاساليب التقنية بينالرسم السريالي.

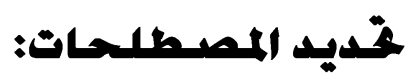

المتغير

\section{(التعريف اللغوي)}

المتغير: هو اسم فاعل لكلمة تغيير والتغيير : غير الثـيء بدلا عن، ويقال غيرت دابتي وغيرت ثيابي

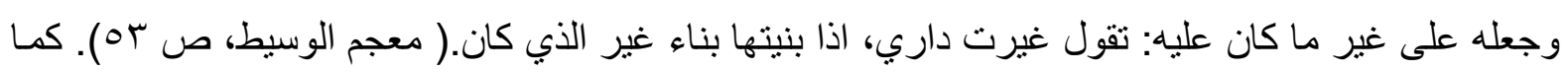

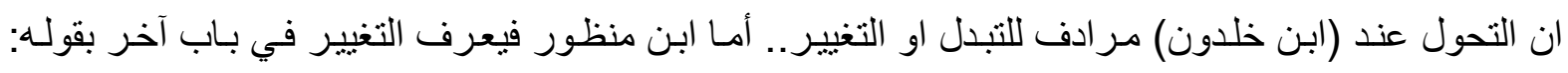

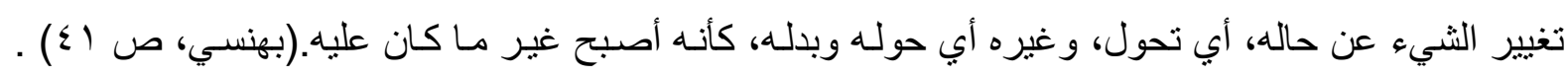

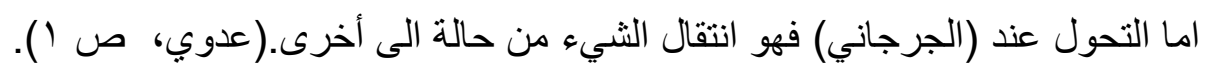


(التعريف الاصطلاحى)

(المتغير ) هو احـ القو انين الرئيسـة للجدل (التحـول مـن الكم الـى الكيف وهو يشـرح كيف وفي ايـة

ظروف تحدث الحركـة والتطور وهذا القـانون الموضـوعي الكلي للتطور بقرر ان تـر اكم التغيرات الكميـة التدريجية التي لا تدرك، يؤدي بالضرورة في لحظة معينة بالنسبة لكل عملية، الى تغييرات جذريـة للكيف و الى وهي تحول على شكل قفزات من كيف قديم الى كيف جديد.(روزنتال، صلV I I). كما تعرف كلمة (التحول) بوصفها مصطلحاً هي انتقال من حال الى حال او هي عملية استبدال حدود منظومة اولى، حد حدا بحدود منظومـة ثابتـة

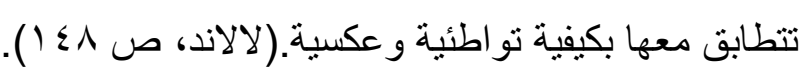

\section{الاوطار الن:طُوي:}

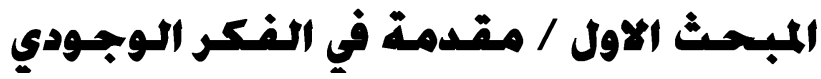

كانت المقدمات الاولى للفلسفة الوجودية ترتبط بوجود الانسان وحياته الاساسية وحريته،لقد أدركت

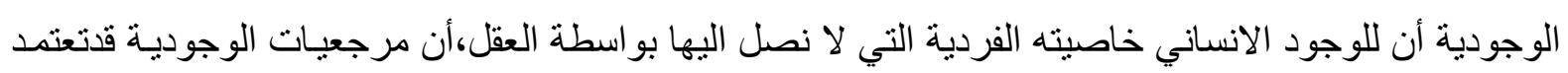
على منهج (الظاهرتية) حيث أن صلب الفكر الوجودي نجد امامنا اتجاهين: الاول يسمى بالوجودية المؤمنة التي

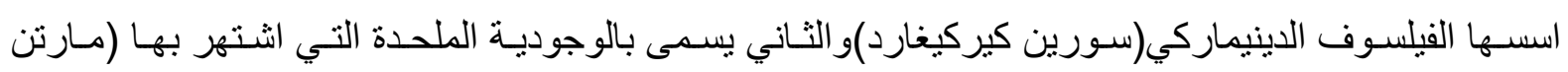
هيدجر) و(جان بول سارنر).

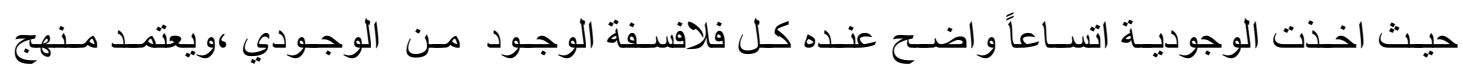
الفينومينولوجي على الخبرة للظواهر في خبرتنا الواعية ثم تتطلق من هذه الحس لتحليل الظـاهرة بها،غير انها لاتدعي التواصل لحقيقة مطلقة مجرد سواء في الميتافيزيقةبل تراهن على فهم الحقائق الاجتماعية نجد ان اسلوب (دوشامب)، فهي نقطة تحول مهمة في الفكر ولاسيما في الاسلوب الحداثوي المتعالق مع فكرة العبث اهدف للوصول الى القو انين والاسس، فأن الاسلوب يعطي نمطاً خاصاً للفنان من خلال (التمرد

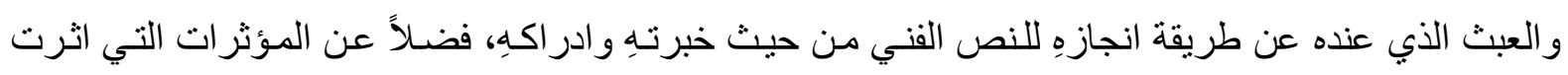
عليه من عوامل بيئية واجتماعية ،ويمكن ان نعد (سلفادور دالي) الفنان السريالي من اوسـع الفنانين تطبيقاً لهذا الانفعال الوجودي مضافاً له رؤية سايكولوجية تتطابق مع اللاشعور و هو بذلك استطاع ان بدمج بتو افقية سـاحرة من حيث النص التشكيلي بين الفكر الوجودي العابث بالأيقونة ومدرسة التحليل النفسي عند فرويد،و هذا ما يؤكدهُ

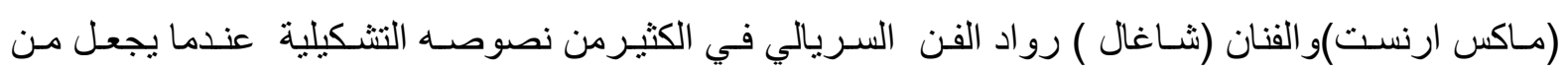
الوجود بناء مزدوج بين رموز مادية وسلوكيات الانسان ذات المنحى الجنسي، انظر الاشكال ( (')(ب).
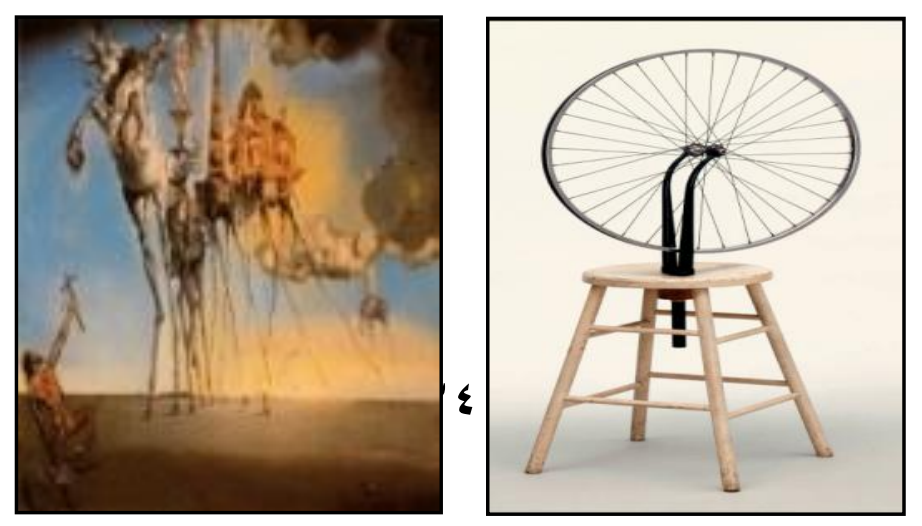
ان الفلسفة الوجودية لها اربع معطيات اثرت تاثير اً كبير في المدرسة السريالية (العدم- القلقـ الحريـة ـ

(الاغتراب)

العدم: ان فكرة العدم التي اعتمدتها الوجوديـة تأسست من ذاتيـة الفرد المنعدم والثـعور بالفــاء والزو ال الذي

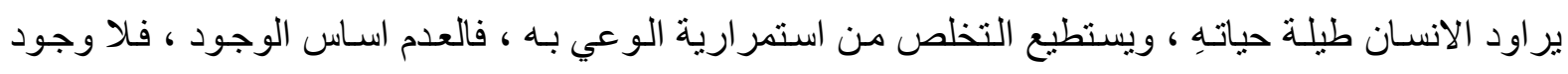

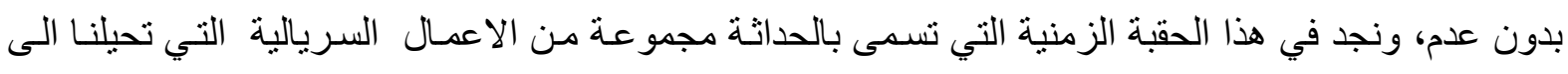

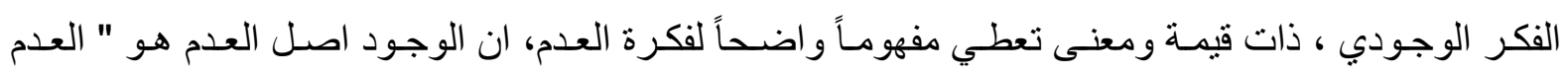
لايمكن ان يكون مصدر هو الوجود في ذاته لان الموجود في ذاته كما رانيا متلى كله بـالموجود كثف سميك ،

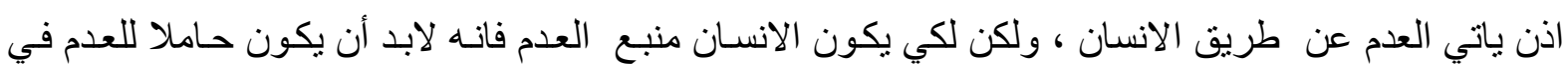
داخل ذاته" (بوشنسكي ، ص: صبr)

القلق: ان القلق الوجودي اخذت من خطاب الفكر الوجودي مساحة مهمه ومؤثرة ، حتى بات القلق يتأرجح بين

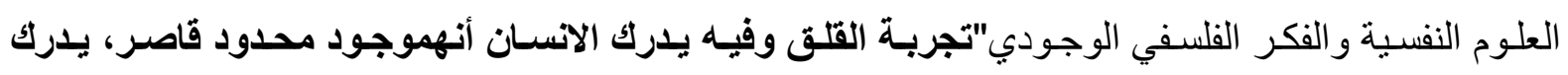

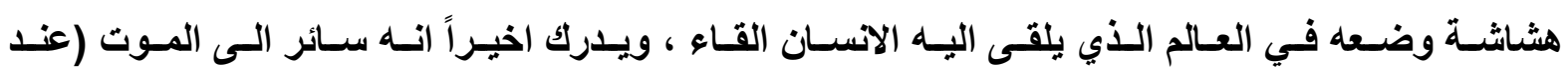

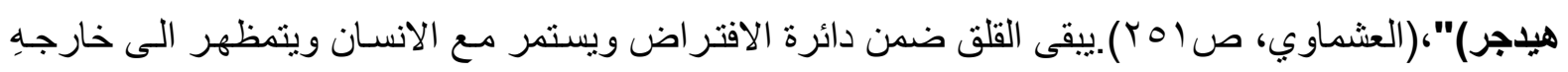
بتعابير مختلفة و لاسيما في التعابير الفنية اذ نجد بعض من الفنانين يجسدون فكرة القلق الذاتي في اعمالهم الفنية بوضوح وفي اثارة التلقي

الحرية: الشعور بالحرية هو الثعور بالوجود فهو اختيار بين عدة نكبات ينبثق من الذات انبثاقـا بديهاً لان الذات هي الامان و الار ادة و الفعل و الحرية ،و ان الحرية " تنكثف ( تكثف عن نفسها ) في القلق، وهو فعل وعي بلهي الانسان بوجود المخصوص الأي يصنع نفسه بنفسه باعتبار عدما، أي فعل الوعي بالحريـة ويهرب الانسـان

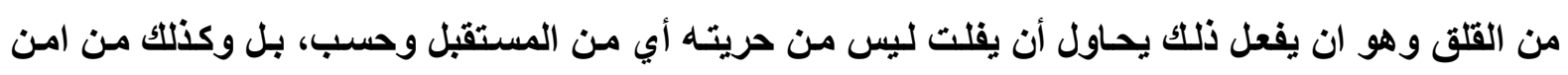
ماضيه" (بوشنسكي، ص ع ب r ). الاغتراب: ان التعالق بين فكرة الاغتراب والفكر الوجودي امر ا واضحا ويتجسد في المفهوم الوجودي للأنسـان

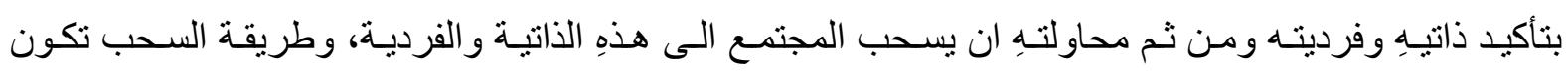
بمشاكسة قوى التحكم بالمجتمع، ان كانت قوى سلطوية او اقتصادية او ثقافية، وفكرة الاغتر اب تُعد منطلق من منطلقات الوجودية، وهي على تعالق تام بالفكر الوجودي من حيث نجدها فعالة في نصوص تثكيلية حداثوية . ان الاغتر اب ظاهرة متحققة في كل ذات بشرية ، لكنها بدرجات تتشكل بمدى مـا يضغط بـه الاغتر اب

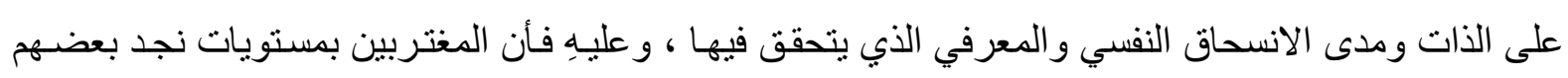
في اعلى حالات الاغتر اب فيكونون بانفصام تام مع مجتمعهم مفارقين الطبيعة الاجتماعي الاغتر اب الذي اشرنا

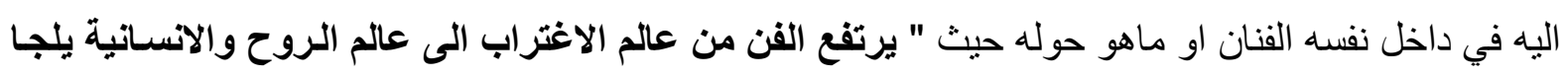

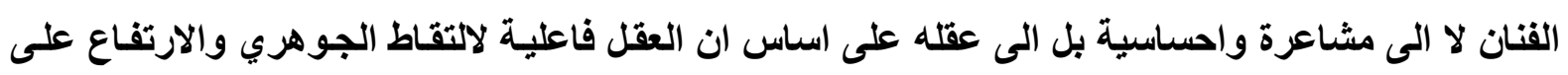

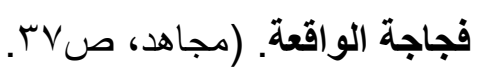

\section{$-r \varepsilon \theta_{-}^{-10}$}




\section{المبحث الثاني / البعد الفـكري و الجمالي للدلالات السريالية}

السريالية التلقائية الخالصة. وتحرر الفكر من العقل وبعيداً عن الانشغال الجمالي أو الخلقي، وهي تستند الى المخيلة، لتعمل وفقاً لاعنماد الو اقعي و الخيالي. أي إنها تعمل وفق منطق الهلوسـة. فهي حركة هدامـة للعقل بفلسفتها فوق الو اقعية، و التي تحتوي (الصدمة، والو هم، والغرابة، و الحلم)، بإعتبار هـا سبلاً جمالية، "كل شيء

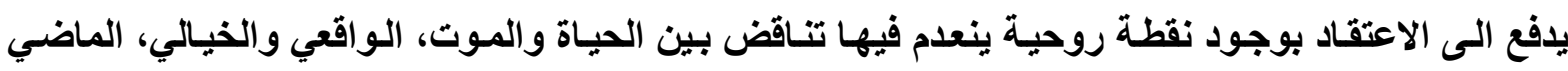
والمستقبل، مـا يمكن إيصـاله ومـا لايمكن، الأعلى والأسـفل، ومسن العبث البحث عن محرك آخر للفاعليـة السريالية غير الأمل بتحديد هذه النقطة.(أونيس، صمی ؟).

إذ إن السريالية بلا شك هي وريثة الدادائية قلباً وقالباً، حيث أخذت عن الدادائية طبيعتها المتمردة عن كلاللا معقول، ومن ثم هي ضد المنطق وضد المفهوم، ممـا أدى الى أن تلهب حمـاس طائفة من الدادائيين السرياليين أمثال(مارسيل دوشامب) و(بيكابيا) ثم (ماكس أرنست) وهو المنتمي الى اتجاه افتر اضي. السريالي لم يتصل إتصالاً كاملاً باللاوعي، وبذلك لم يفهم الواقع، لان اللاوعي هو طريق لفهم الواقع، وان ذاتيـة الفنـان السريالية ستموت وييقى حالمـاً فقط دون الرجوع الـى حالـة الوعي. فـالوعي و اللاوعي هــا

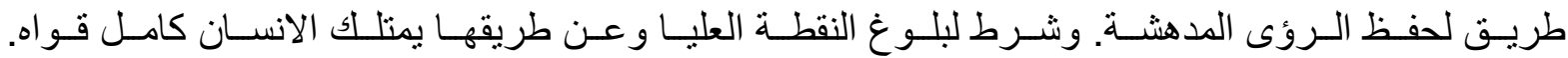
اعثرف(دالي)يقول" لا غرابة في ألا يفهم الجمهور لوحاته، إذ هو نفسه لا يفهمها"(ايفون، ص (V)). في نفسه مقاربة مع الفينومينولوجيا، وهو يُعد علامة مميزة انمتازتْ بها السريالية، في وقت لاحق في

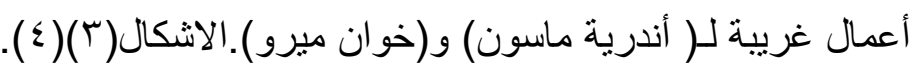
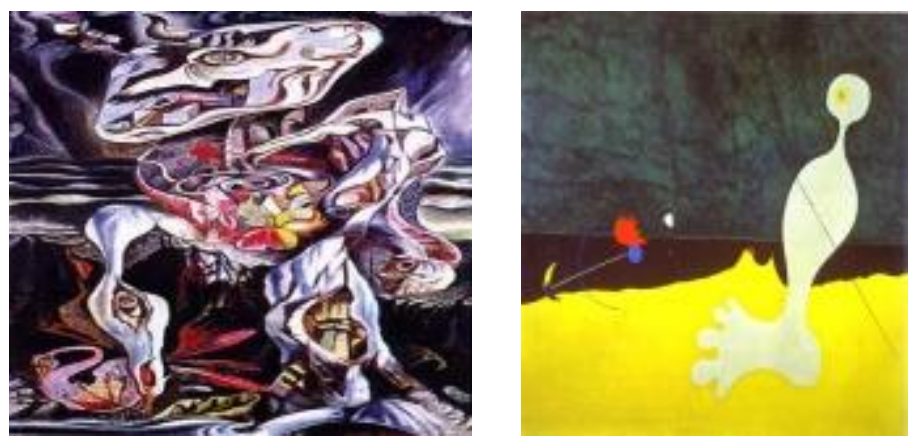

إنَّ السريالية" لا تجنح نحو نكران العالم الخارجي الموضوعي وحسب، بل تنحى نحو مفهوم تثكيلي لتكثف عن واقع مُزاح ومتحول لا علاقة له مـع الواقع الخـارجي ولا مـع قوانين الفن ولذلك" نرى رسـاماً مثل(شاغال )يستعمل في اللوحة الواحدة صور اً ذهنية في مقابل صور مادية فكثيراً

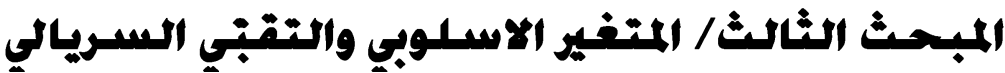

ان مفهوم الاسلوب مفهوم قديم يعود الى بدايـة التفكير الملحمي في الثـرق والتقكير الادبي في اوربـا ويظهر اكثر ارتباطا بالبلاغة ويعد الاسلوب جزءا من صنعة الاقناع.، ارتكزت السريالية في بداية انتشـار ها 
على اربعة فنانين وبداتتجذز فروع السريالية من خلال اسالييهم المختلفة الوحدة عن الاخر، سوف نقوم مفي

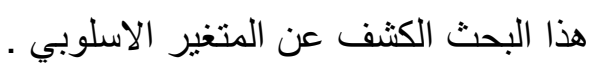
مارك شـاغال:يعد رائد في الفن السريالي هو و الفنان ( شيريكو ) في التمخيل ، فكانت أعمالهما في

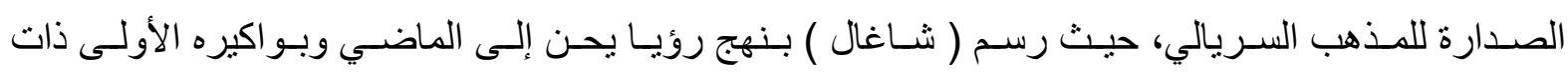

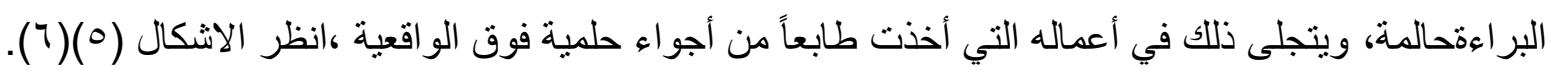
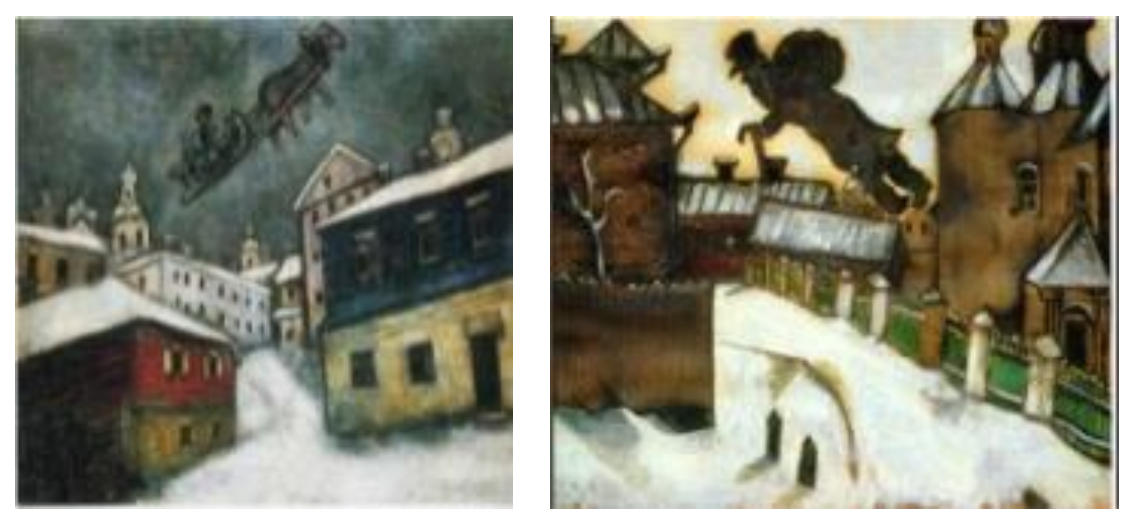

ماكس ارنست: بعد احد ممثل الذي تحول من الدادائية إلى السريالية، تتضح محاو لاته في النفاذ إلى الحقيقة

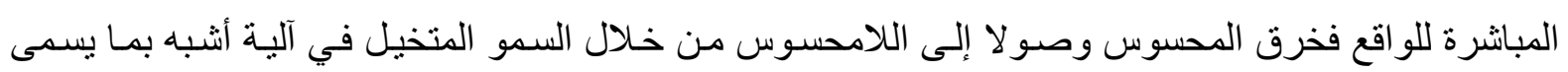

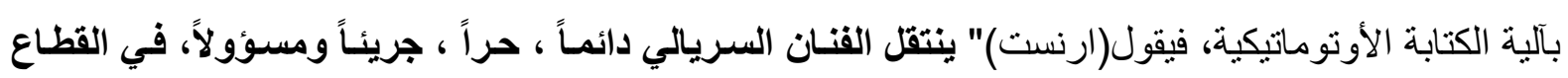

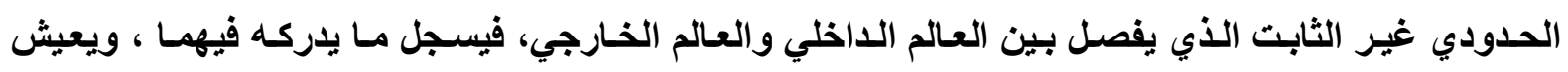

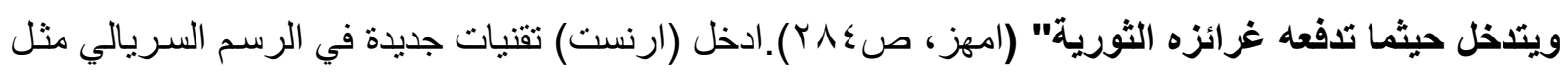

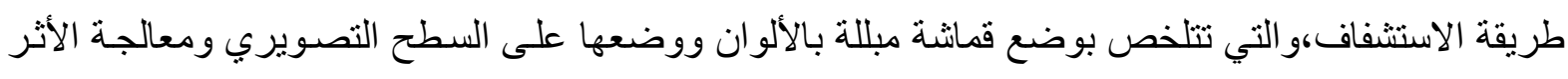

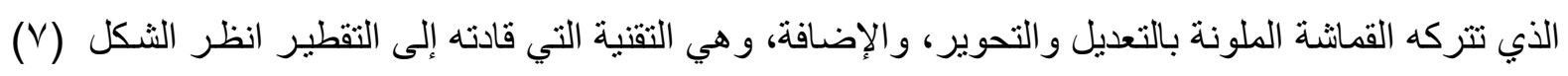
$(1 \cdot)(9)(\wedge)$
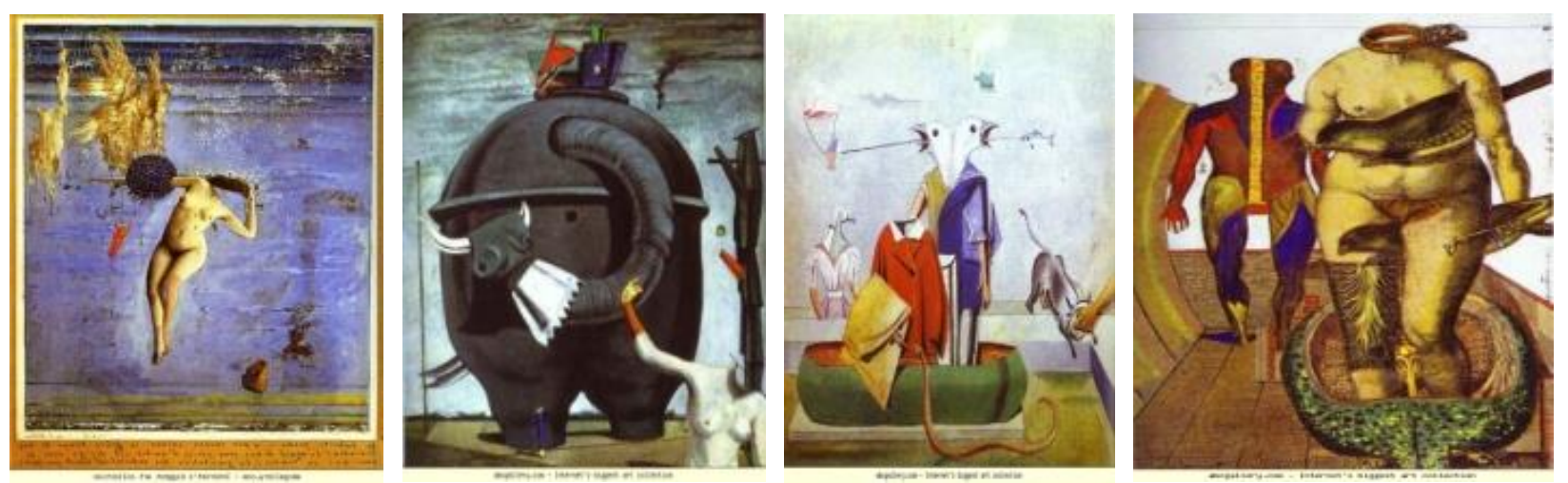

سلفادور دالي: يعدهذا الفنان الفن واحداً من ممتلي المدرسة السريالية في الرسم. فالتأليف التي يبتكرهـا الفنان

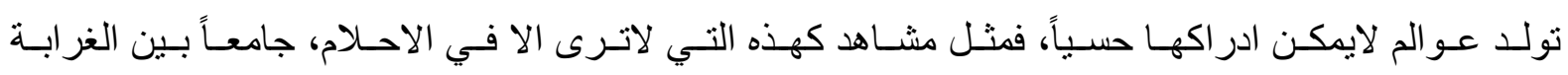


و اللامألوفبتقنية تذكرنا بالكلاسيكين الاو ائل، الفنان شأنه شـأن الفنانين الذين سبق ذكر هم في تطلعهم الى ربط الفعل الابداعي في الرسم مع قو انين كلية كونية، والفن يصبح في نهاية الامر ينتمي الى المطلق، فباعتمـاده على مـا اسماه "بالنشـاط الهندباني-النقدي، (Activate paranoiaqde, critique) الذي عده منهجاً تلقائياً

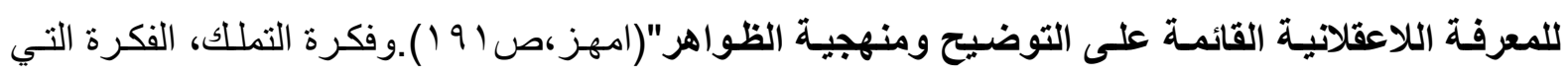
تتملك الانسان وتجعله يعتقد بأن الاشياء غير الحقيقية حقيقة واقع،وهذا يتضح في أعماله السريالية، لقد استخدم (فنان) التشويه ومظاهر الانحطاط و الاضطر اب ليعكس الأمر على الحالـة الثقافية والاجتماعيـة بمحاولة ربط طروحات التحليل النفسي لما يشوب الوضع العام في الثقافة والسياسة في مرحلة مـا بين الحربين انظر الثكل
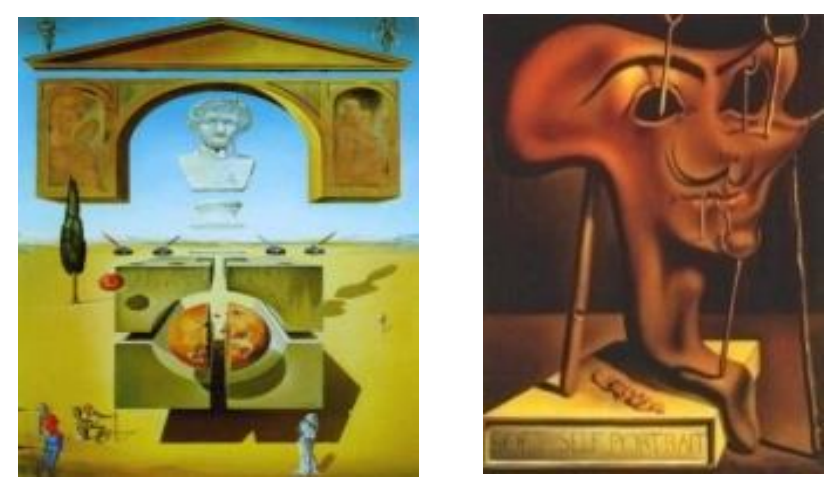

و هكذا اتبع ( دالي) تقنية الإيهام الو اقعية التفاصيل (تقنية رجعيـة) حسب تعبيره، فهو يستخدم المجهر

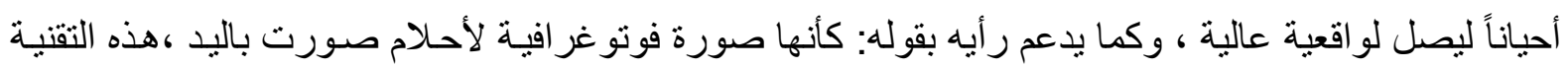

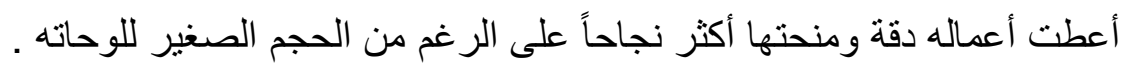

(خوان ميرو):جرد ميرو الاشكال الحسية واحالها الى مجموعة من التر اكيب المركزة على العناصر الاساسية في الرسم كالخط واللون المقتصد، مما يضع الرسم امام واقع مطلق في سحريته وخياله. فباعتمـاده على التلقائية و اللاشعور وضع ميرو نفسه على الدرب الذي خطه السرياليون في بحثنهم عن الحقيقة المجردة. فاثكاله التي يدير ها (بمخيلة لايقوى شيء على كبحها خلق ميرو رجالاً صغار اً بدائيين يضعهم جنباً الى جنب مع طيور

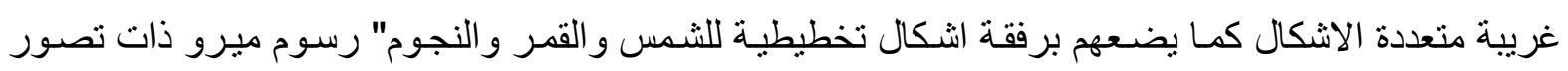
كوني فقضاء لوحته يؤالف فيه بين الثمس و الانسان والحيوان و النبات انظر الاشكال ( ب ا (ع ( ).
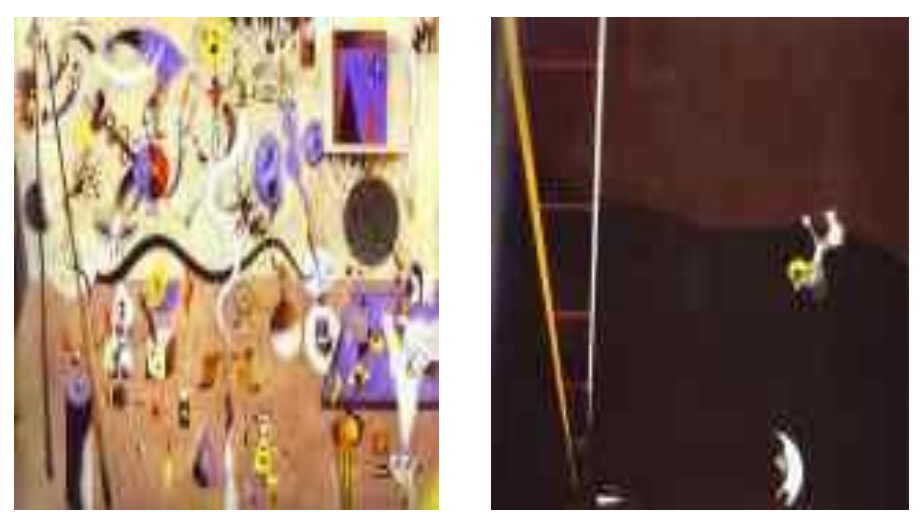

$-\mu \varepsilon \wedge$. 
فرسومه تمتاز بالتلقائية وعدم وضـع أهمية للرموز الهندسية والواقعيـة ، فأصبح أسلوبه أكثر عفويـة وتجريدية، لأيمانه بالآلية والمفاجئة، فأخذت البقع اللونية بعداً جمالياً ظهر على السطح التصـويري في أعماله الفنية الآلية،انظر الثكل (0 (1) (7 ( ).
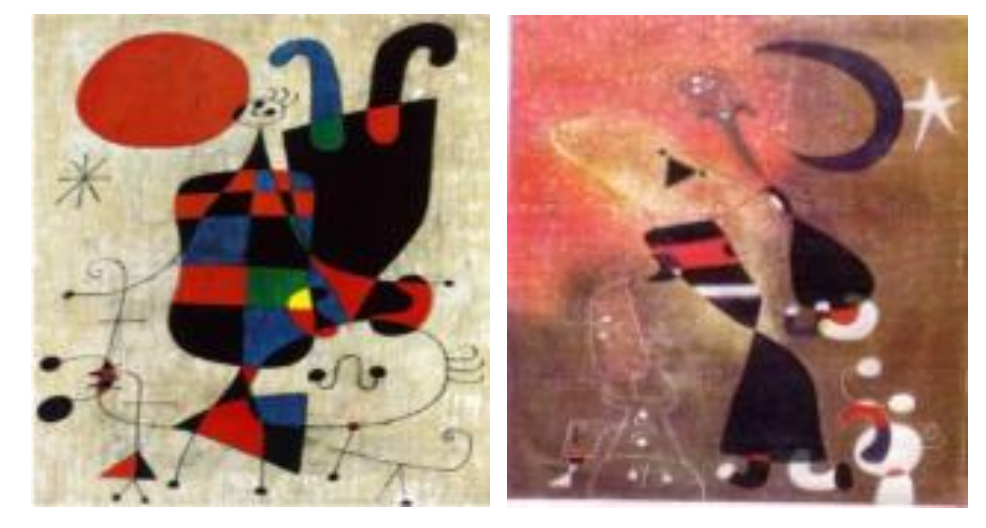

\section{مؤشيرات الإطار الن:طري:}

ا. أثّرت حركة الأفكار على المنجز التشكيلي للفنان السريالي بعدّها إطـار اً ضـاغطاً يحتوي مجموعة من الاستعار ات التي تم تركيبها في منجزه البصري، وتتجلى أنساق السريالية الفني عن تلك الاستعارات المتحققة بنائياً بفعل تقنيات الاخر اج الفني. r. من خلال على الاطلاع على اعمل كل من الفنانين السرياليين استخدمو عدة تقنيات لتشكيل اعماله منها:

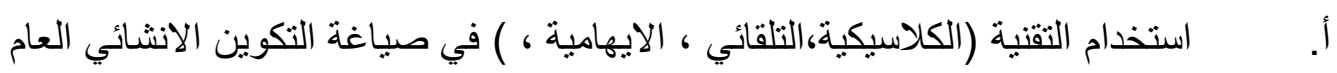
ب. اتبع تقنية (لتكر ار استر اتيجية) في السطح البصري ج. والتقنية (التزيين الطباعي،الرسم الأكاديمي ) د. وتقنية(حبر على ورق، و الزيت على قماش الكانفس ) ) ه. التقنية في( الفر اغات والتباينات)

\section{ابجراعات البهحثث}

مجتمع البحث: نظر السعة مجتمع البحث الحسالي حيث يتكون من أعمال الرسامين السربال ضمن حدود الفن المعاصر ، قامت الباحثة، وحسب الحدود الزمنية باختيار (9 ())، حيث تحدد المجتمع بمنجزات الرسامين. نماذج البحث: تم تحديد عينة البحث على نحو قصدي باختيار ات تعتمد المتحول الاسلوبي في الفن التشكيلي ذي

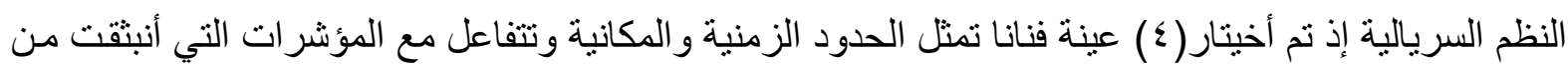

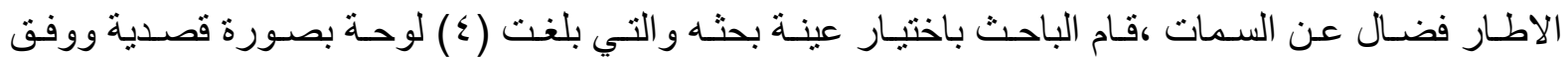
الضرور ات.

تم للباحثة اختيار عينة البحث منابزر رواد هذه الحركة ، ما ورد في مجتمع البحث ،حيث تم الاختبار قصديا(purposive) مع مر اعاة إن العينة المختارة ضمن اطار هذة الحركة، وقد اختير (ع) عملا فنيا. 
منهج البحث: أعتمد الباحث أسلوب تحليل المحتوى ضمن رؤية علمية نفسية وفلسفية في تحليل العينات والذي يتماثىى وتحقيق الهدف الذي جاءت من اجله الدراسة الحالية.

أعتمــ الباحث استمارة تحليـل المحتوى عن منظومـة شكلانيةومضـامينية تجعـل مـن العناصـر الفنيـة وحركة العناصر من خلال علاقات التكوين و التحليل الحاصل على مستوى الثكل و اللون و الزمـان و المكان وتعبيرات ذلك من خلال عدد من المحاور هي الانا القلق والاغتراب و الوجود.

أداة البحث: إستعان الباحث بالمؤشرات التي تحققت من مباحث الاطار النظري كمعـادلات تحليل تعتمد فضلاً

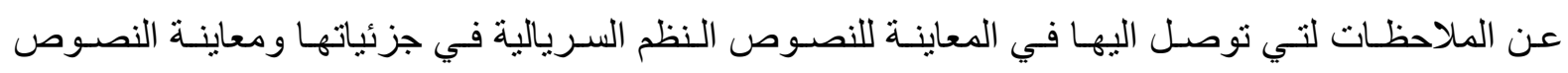

باجمعها.

أداة جمع البيانات: اعتمد الباحث على جمـع المعلومـات والبيانـات المتعلقة بالاعمـال(عينـة البحث) على دراسـة

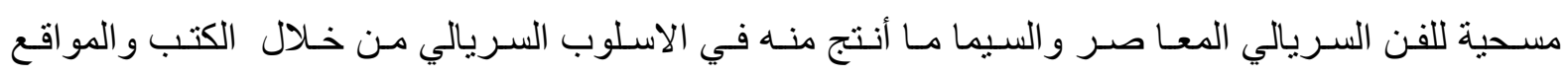

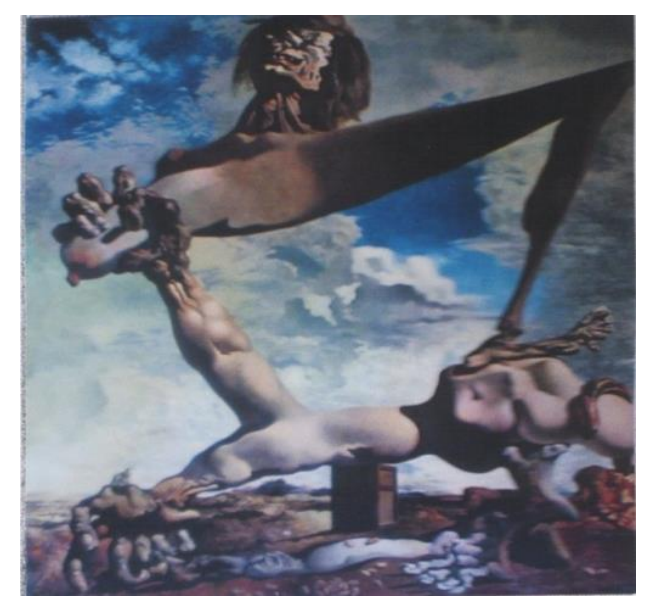

الالكترونية.

إن هذا العمل من انعكاسـات الحرب التي شنّهها نظـام الحكم في أسبانيا ضـد ثوّ ار إقليم الباسك بمعونـة ألمانيـا النازيـة، لهذا فهو عمل يحفل بالمضـامين ، الأمـر الذي يقرره عنوان اللوحـة، تتحوّل إلى جسد بشري

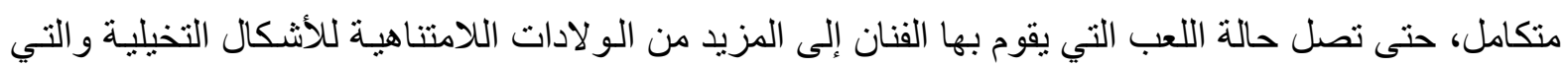
تكثفف بدور ها عن عو الم اللاوعي، وهو هنا يستفيد من الدراسات النفسية لـ(فرويد) و(يونغ)، لوحة الفنان التي كثنف عن نر ابط غر ائبي بين الوعي و اللاوعي، إذ تظهر رؤيته الذاتيـة المنبعثة من

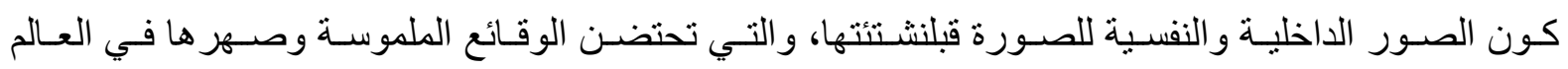

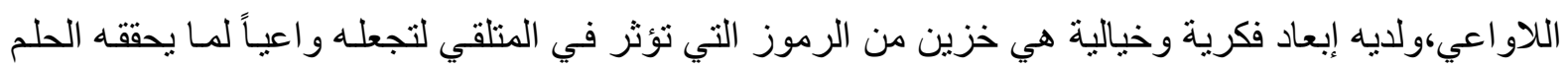

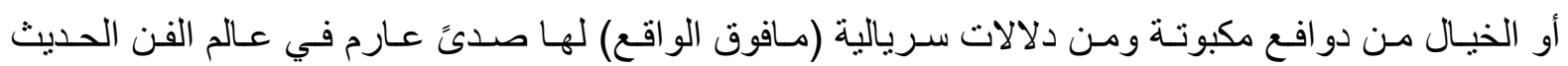
،سلفادور داليأتتج بقدرته التصـويرية الدقيقة والجو المرعب للوحاته، إبداعات فنيـة، سيبقى تأثير هـا ثابتأ،وتبلغ الصورة الحلمية عند السرياليين مستواها الجمالي في اللاشعور (العقل الباطن) الجمعي. 


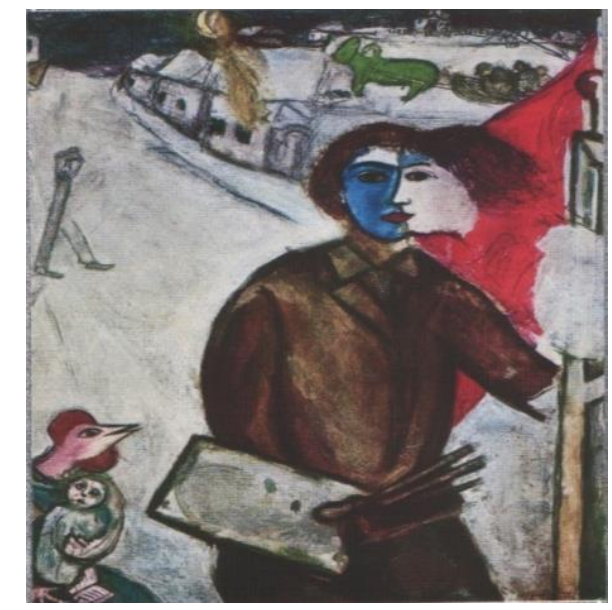

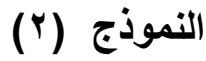

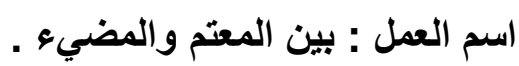

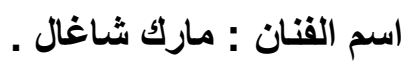
المادة : زيت على كانفاس . القياس : V

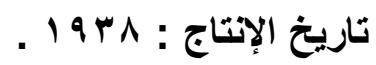
العائدية : هبة خاصة لمدرسة غير حكومية ، بيرن . يصوّر الفنان في هذه اللوحة أشكالاً تم تحوير ها واختز الها، كما تم تركيب بعضـها البعض، فنتج عنها شخصية بوجهين ويد مبتورة، واليد الأخرى تحمل فرش الرسم ولوحة الألوان، وشخصية أخرى بر أس طير، تحمل طفلاً. بينما كثفت خلفية المشهر عن أشكال لا مألوفة، إذ أصبح الحيوان الذي يسحب العربـة شكلاً خر افياً ذا لون أخضر ، بينما تحوّل عمود المصباح إلى هيئة بشرية بساقين.

ينطلق الفنان من أرضية نظرية نفسية وفلسفية جمالية تحاول أن تكون تطبيقاً لنظريـات التحليل النفسي و التداعي الحر للدخزون اللاشعوري التي جاء بها (فرويد)، كما تأتي كرد فعل للحروب و الحوادث المأسـاوية التي آلت إليها البثرية جرّاء ثقافة القوة و المـادة، لذا كانت لوحسة الفنان لسـان التمرّد الر افض للو اقع المُخيّبب للآمالومن ذلك تأرجح الفنان في اتجاهـه الاسلوبي بين التعبيريـة والسريالية، إذ عمل على هدم مقولـة العقل ، ليحل اللاعقل ولتحل الضرورة الوجدانية التي من خلالها بـان مسعى الذات الحرة نحو هدم نظسام القيم كاملاً،

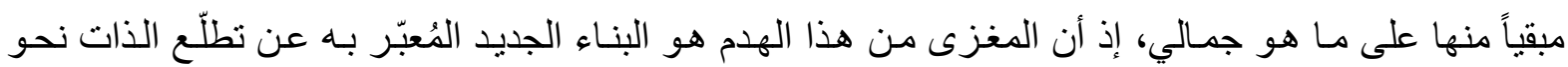

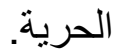

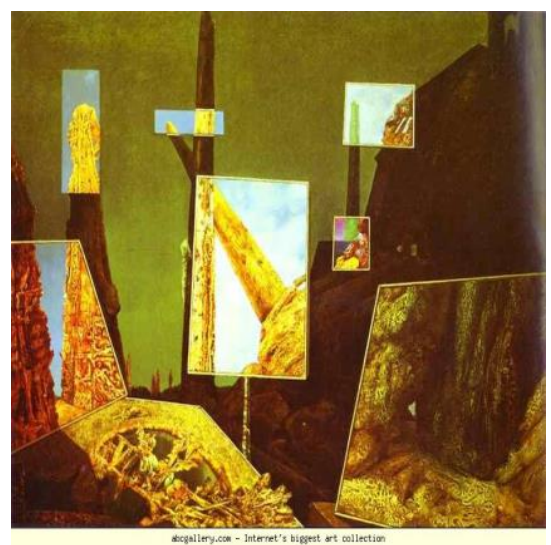

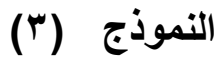

اسم العمل : اليوم واليل . اسم القنان: ماكس ارنست المادة : زيث على كانفاس . القياس : : إس :

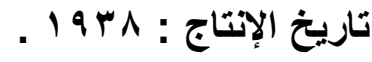

\section{Private collectio: العائدية}

يصور ارنست العديد من الثنمات المختلفة والمنتشرة على كل مساحة اللوحة وباسلوب بديع، إذ احتوت اللوحة على رسم اليوم و اليل رسم بخطوط هندسية تعطي الأحساسبمرونه الخط و أنسيابيته بشكل أوتوماتيكي

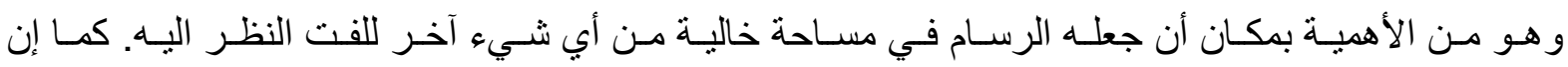
اللوحهأحتوتعلنتر اكيب هندسية عديدة فقد فلم الفنان بتوزيع الوحات في اللوحه كائنها مريـا تعكس كل واحدة. 
رؤية جديدو عن الاخرى، حيث رسم خطاًافقياً فاصلاً بينه وبين بقية اللوحات بدت سمائه على خلاف بقية اللوحه مشرقة ويوضح ذللك وجود سماء صافي وراء الاشجار والجبال التي تسند تلك الاعمـال ورسم ارنست "

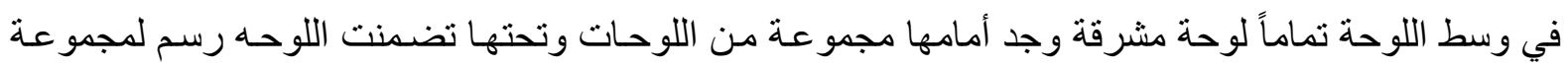
من الاعلام موجودة أعلى يسار اللوحة تضمنت أيضاً وجود سماء صافي التي استخدمها ارنست كرمز للضوء ولنهاء و الحياة.

أستلهمها من أسلوب التطريز الالماني في القرون الوسطى والذي وجد طريقه في مـا بعد الى أعمالا

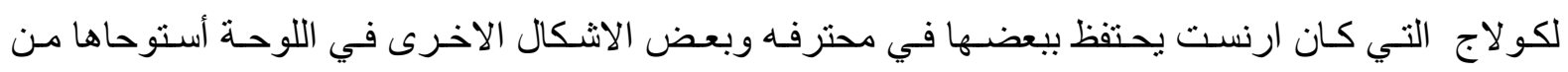
رسومات. كما ان العين التي تظهر في أعلى الجبال الكبيرة الى اليمين لها أصل في الفن المسيحي القديم.

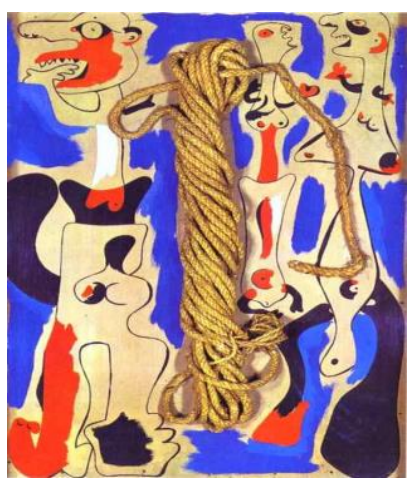

(النموذج (1)

اسم اللوحة / حبل والناس اولاً

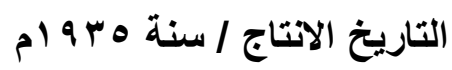
المادة / زيت وحبال على الخش

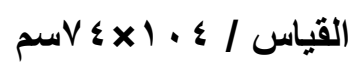

العائدية / اللوحه مستعاره من اميل فرناند زميل مجموعة خاصة برشلونة. ان لوحة حبل والنـاس اولاً والتي رسمها "ميرو" تعتبر خروجاً عن المـألوف حيث قال "ميرو" اريد

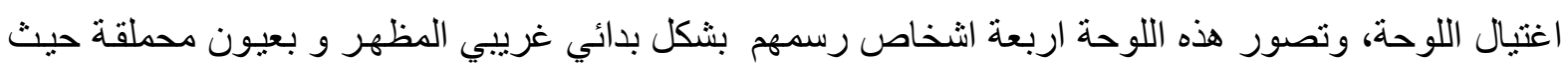
بدت مسحة من الثر على قسماتهم و اقتصر رسم هذه اللوحة على ستة ألوان فقط هي الاسود و الأزرق و الأحمر و الأبيض و الاصفر والاوكر. من النئ.

لقد تحدى الفنان في هذا العمل كل الاسـاليب المتبعة في فن التصـوير وذلك لتنشيط و اعـادة تحديد اسلوبه، فقد استخدم مواد مختلفة لاظهار ماديـة الاثياء الملموسـة في اللوحة كمـا ان التنوع في استخدام هذه المو اد يوكد معارضـة الفـان السير في العمل على نمط موحد وان حزمـة الحبـال في هذه اللوحـة تعتبر من المواضيع العدوانية التي استعملها في السعي لتحقيق هدفه فوجود الحبل في اللوحة اضـافة الى رسم الاشكال بهذه الطريقة يثير فينا احاسيس من الخوف بحدوث امر رهيب، إذ إن طرف الحبل الذي يتدلى من اعلى الحزمـة له مدلو لات كثيرة فلم يضعة الفنان بشكل اعتباطي او غبر مقصود، فقد قام الفنان بتثبيت الحبل فوق رقبـة احدى فئي النساء الموجودة في اعلى اللوحة في اشارة الى عملية الاعدام ،اسلوبه مـابين التجريد والتشكيل وجذريـة التقليد فابتعد فيه عن الجمالية بسبب حالته النفسية فالثكل لدى "ميرو" لايحـاكي نموذجاً مرئياً و إنمـا يمتاز بـالخلق و التجديد لانه وليد حالات نفسية متعددة فهو نتاج متخيل نـابع من روح الفنان و على هذا النحو تتحرك دو افع

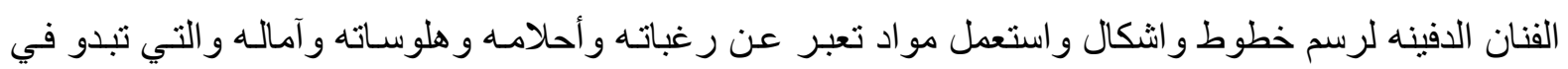
صور خيالية خر افية صعبة الفهم على المشاهد 
إن الفنان السريالي حقق في بناءاته التشكيلية نظم سريالية واضحة عن طريق التنوع الإسلوبي في عمليات التشكيل وطريقة تحليل المعطيات و أعادة تركيبها بصيغة تكاد تكون ر افضة للو اقع و الو اقعية بكل إثكاله: ا. . غياب العقل وسطوة مخيلة الفنان الناتجة عن تعدد الهلوسة الار ادية ليكثف عن إبداعات فنية تكون في ذاتها أكثر مقبولية عن الواقع المادي.

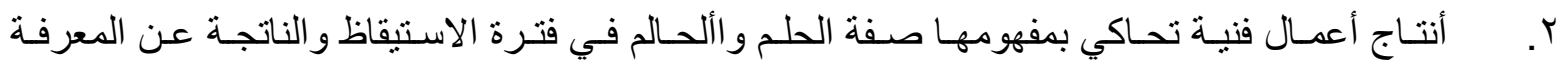
المتر اكمة و الخبرة التي تحقق قيم إبداعية مميزة وتمتلك خاصية الاستفزاز و إثارة الجدل. r. إن الصورة التراجيدية التي أفصحت عنها الاعمـال السريالية وتحقق نوعاً من الابمو إعتصـار الذات وتتجه بمنحاها نحو طابع التهم و الازدراء و الانسحاق، التي تثير المخاوف و القلق والذهول لدى المتلقي فهي بذاتها تتتج نصاً جمالياً و أبداعياًِيكون صورة من صور التغيير .

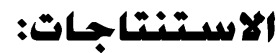

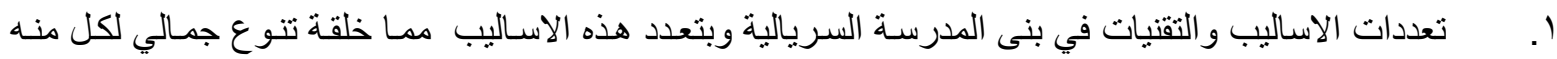

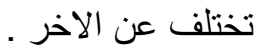

r. . ت تجذر السريالية مفاهيمنها من الفلسفة الوجودية التي اعتمدت منخلالالهلالعدام و القلق والاحرية و الاغتراب . r. ارتكزت المدرسة السريالية على اربعة فنانين التي يمكن اعتبار هم اعمدت المدرسة السريالية اوجذو الاسلوبي الذي اعتمدها الفنانين من بعدهم و هم كل من ( شاغال ، ماكس ارنست، دالي ، ميرو ا. ؛. ظهور اكثر من من متغايرة الادائي بين فنان واخر اعتمدة كل اسلوب على قوة قوة الابداع لكل واحد منهر التي اظهرت فيها تمايز ها بشكل و اضح.

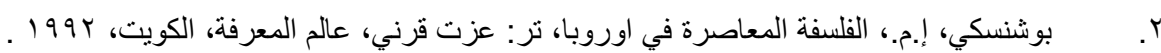

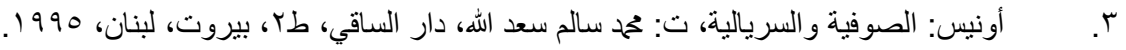

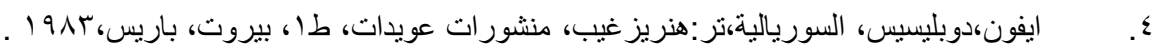
0. امهز ، محمود : التيار ات الفنية المعاصرة ،د: شركة المطبو عات للتوزيع و النشر لبنان.

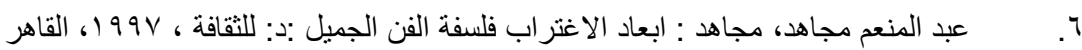

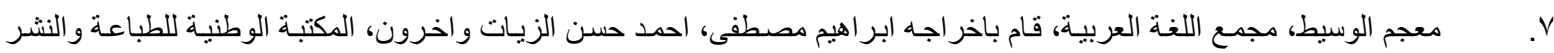

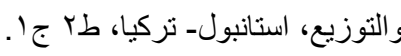
^. بهنسي، عفيف، معجم مصطلحات الفنون، دار الر ائد العربي، بيروت، لبنان.

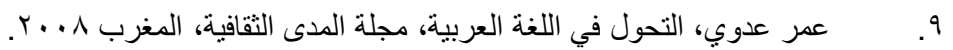

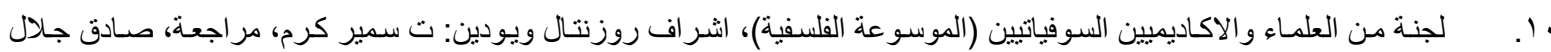

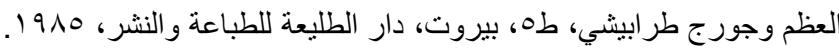

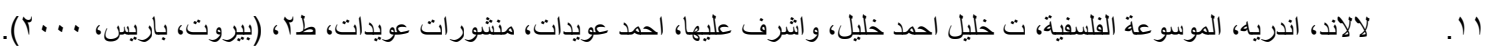

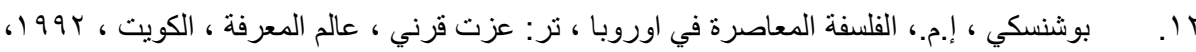

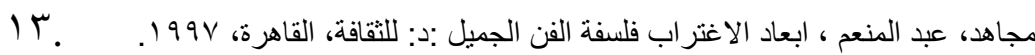

